\title{
Molecular characterization of novel sulfotransferases from the tick, Ixodes scapularis
}

\author{
Sivakamasundari Pichu ${ }^{1 *}$, Emine B Yalcin², José MC Ribeiro ${ }^{3}$, Roberta S King ${ }^{2}$ and Thomas N Mather ${ }^{1}$
}

\begin{abstract}
Background: Ixodes scapularis, commonly known as the blacklegged or deer tick, is the main vector of Lyme disease in the United States. Recent progress in transcriptome research has uncovered hundreds of different proteins expressed in the salivary glands of hard ticks, the majority of which have no known function, and include many novel protein families. We recently identified transcripts coding for two putative cytosolic sulfotransferases in these ticks which recognized phenolic monoamines as their substrates. In this current study, we characterize the genetic expression of these two cytosolic sulfotransferases throughout the tick life cycle as well as the enzymatic properties of the corresponding recombinant proteins. Interestingly, the resultant recombinant proteins showed sulfotransferase activity against both neurotransmitters dopamine and octopamine.
\end{abstract}

Results: The two sulfotransferase genes were coded as IXOSC SULT 1 \& 2 and corresponding proteins were referred as IXosc Sult 1 and 2. Using gene-specific primers, the sulfotransferase transcripts were detected throughout the blacklegged tick life cycle, including eggs, larvae, nymphs, adult salivary glands and adult midgut. Notably, the mRNA and protein levels were altered upon feeding during both the larval and nymphal life stages. Quantitative PCR results confirm that IxosC SULT1 was statistically increased upon blood feeding while IxOSC SULT 2 was decreased. This altered expression led us to further characterize the function of these proteins in the lxodid tick. The sulfotransferase genes were cloned and expressed in a bacterial expression system, and purified recombinant proteins Ixosc Sult 1(R) and 2(R) showed sulfotransferase activity against neurotransmitters dopamine and octopamine as well as the common sulfotransferase substrate $p$-nitrophenol. Thus, dopamine- or octopaminesulfonation may be involved in altering the biological signal for salivary secretion in I. scapularis.

Conclusions: Collectively, these results suggest that a function of Ixosc Sult 1 and Sult 2 in Ixodid tick salivary glands may include inactivation of the salivation signal via sulfonation of dopamine or octopamine.

\section{Background}

Ticks are hematophagous arthropods, notorious as vectors of human and animal pathogens [1]. Diseases transmitted by ticks are global medical and veterinary public health problems [2]. Ixodes scapularis, known commonly as the deer tick or blacklegged tick, is the major vector for Lyme disease, babesiosis, and granulocytic anaplasmosis to humans and domestic animals in the United States. Ticks and other blood-feeding arthropod vectors manipulate host hemostatic and immune responses by secreting molecules from their multifunctional salivary glands. Blood feeding by ticks requires

\footnotetext{
* Correspondence: au_sudha@yahoo.com

${ }^{1}$ Center for Vector-Borne Disease, University of Rhode Island, Kingston, RI 02881, USA

Full list of author information is available at the end of the article
}

prolonged contact with host tissues and blood, and it has been suggested that the adaptation of ticks to their natural host has resulted in evolution of an appropriate set of salivary components allowing the tick to evade host immunity and prevent coagulation at the feeding site to successfully obtain its blood meal [3]. The blood feeding cycle of larval and nymphal Ixodes scapularis typically extends for three to four days, while that of the adult female blacklegged tick lasts approximately six days; during this time the tick alternately secretes salivary fluid into the host and takes up blood from the host [4]. Successful blood feeding must require endogenous signalling molecules within the tick to turn on and off salivation and control the release of some 300 secreted salivary proteins into the saliva [5]. One possible strategy for reducing tick-transmitted disease 
incidence could involve manipulating tick salivary secretion so as to interrupt or shorten the duration of host attachment or blood feeding. Accordingly, this research is focussed on elucidating biochemical pathways of two sulfotransferase genes that may be involved in tick salivation and pathogen transmission.

Sulfotransferases catalyze transfer of a sulfonyl moiety $\left(-\mathrm{SO}_{3}\right)$ from the universal donor 3'-phosphoadenosine5 '-phosphosulfate (PAPS) to an oxygen or nitrogen acceptor, resulting in production of a sulfate ester. Historically, sulfotransferases have been classified by their sub-cellular localization as either cytosolic or membrane bound [6]. In general, cytosolic sulfotransferases accept relatively small molecules as substrates, while the membrane bound sulfotransferases utilize macromolecules [6-9].

Although a number of sulfotransferase genes are registered in various invertebrate genome databases, only a few invertebrate sulfotransferases have been characterized. Cytosolic sulfotransferases have been characterized from the nematode Caenorhabditis elegans [10] and from the arthropods Bombyx mori [11], Spodoptera frugiperda [12], and Drosophila melanogaster $[13,14]$. C. elegans contains a glycosaminoglycan membrane bound sulfotransferase with heparan-2-Osulfotransferase activity [15]. Membrane bound tyrosylprotein sulfotransferases have been characterized from Drosophila melanogaster and from C. elegans [16]. Specifically in salivary glands, tyrosylprotein sulfotransferases have been characterized from human saliva [17] and rat salivary gland tissue $[16,18-20]$. Thus, precedent exists for both cytosolic and membrane-localized sulfotransferases in arthropods, and in mammalian salivary glands.

Sulfotransferase enzymes modulate the activity of many hormones and proteins; in humans and other mammalian species, some are involved in regulating immune responses and blood coagulation [6,9,21-25]. Recently, we predicted that dopamine and octopamine could serve as substrates for tick-derived sulfotransferases [26]. Dopamine is known to stimulate secretion of tick saliva through a neurochemical mechanism. Tick salivary fluid secretion is controlled via a dopamine D1 receptor and cAMP dependent protein phosphorylation cascade following salivary gland stimulation by dopamine released from nerve endings [27]. Moreover, endogenous dopamine has been identified in salivary glands of the ticks Rhipicephalus microplus and Amblyomma hebraeum $[28,29]$. Octopamine also exhibits neuromodulatory functions in arthropods [30]. Thus, precedent exists for sulfotransferase enzymes to impact host hemostasis as well as modulate tick salivary or host components which regulate salivation, immune response, or blood coagulation.
Our recent report showed the three dimensional structural conservation of two novel tick sulfotransferases (Ixosc Sult 1 and Sult 2) and its ligand docking. Predictions from the modelling were tested and confirmed using native tissue enzyme homogenates from larval and nymphal stage blacklegged ticks [26]. In this present study, we identify the genetic expression of two cytosolic sulfotransferases throughout the tick life cycle and characterize the expressed recombinant proteins. Interestingly, we observed differential gene expression between the two sulfotransferases during blood feeding, and that their recombinant enzymes effectively sulfate neurotransmitters dopamine and octopamine. Taken together, the observed differential expression of these two sulfotransferase genes and the resulting protein affinity for neurotransmitters involved in tick salivation suggests that Ixosc Sult 1 and Sult 2 may play roles in tick salivation and pathogen transmission processes.

\section{Results}

\section{Amino acid sequence comparison}

The sequence alignment of the two Ixodes sulfotransferases (Ixosc Sult 1 and 2) and related mammalian cytosolic sulfotransferases are shown in Figure 1. The SULT_MOTIF on Figure 1 indicates the residues which make up the cytosolic sulfotransferase amino acid sequence motif regions. Thus, the amino acid sequence comparison confirms that there is presence of conserved domains of cytosolic sulfotransferases on both Ixosc Sult 1 and 2.

\section{Transcriptional expression of IxosC SULT 1 and SULT 2 genes and gene products}

To shed light on the transcriptional control of the two genes during different life stages of I. scapularis, we used real-time quantitative RT-PCR to amplify RNA isolated from pooled unfed and blood-fed whole larvae and nymphs, as well as the salivary glands and midguts dissected from both unfed and blood-fed adult stage ticks. Usually, the feeding time varied between 48 to 72 hours. Expression levels were normalized using the constitutively expressed $\beta$-actin transcript as a standard. Results showed that the SULT 1 was increased during feeding 1.5 fold in larvae and 1.4 fold in nymphs. In contrast, SULT 2 was decreased during feeding by 1.5 fold in larvae and 2.6 fold in nymphs as shown in Figure 2A and 2B. Furthermore, the difference in transcript abundance for SULT 1 and SULT 2 were statistically significant, $\mathrm{p}$ $<0.03$ for SULT 1 and $\mathrm{p}<0.01$ for SULT 2 during larval stages between unfed and fed, where as $\mathrm{p}<0.008$ and $\mathrm{p}<0.03$ for SULT 2 during nymphal stages between unfed and fed, respectively (data not shown). Briefly, as feeding initiated in larval ticks, SULT 1 expression increased whereas SULT 2 expression decreased during 


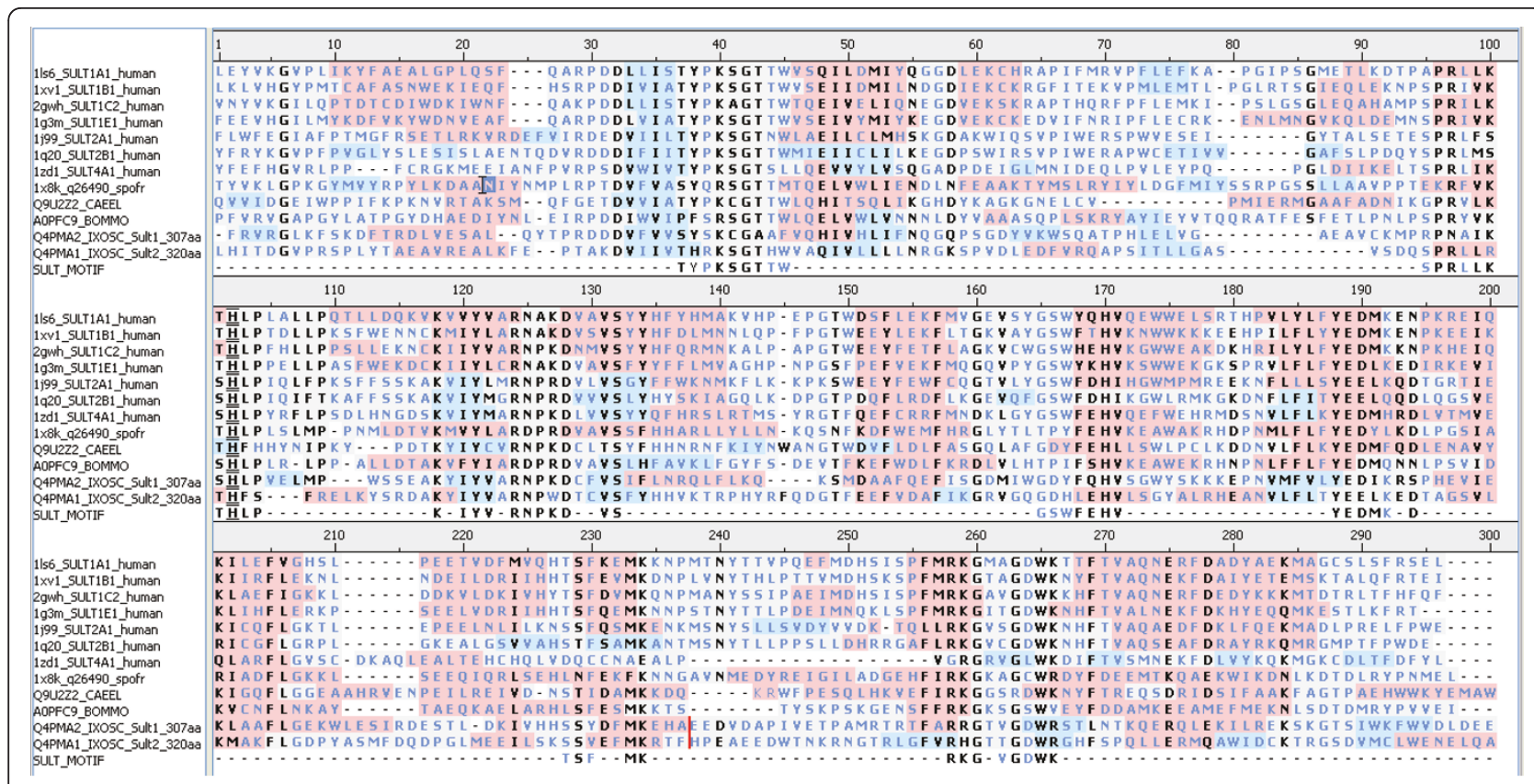

Figure 1 Sequence Alignment of Ixosc Sult 1 and 2 with selected known cytosolic sulfotransferases. Ixosc Sult 1 and 2 are designated as q4pma2_Ixosc_Sult1_307aa and q4pma1_IXosc_Sult2_320aa, respectively. Human sulfotransferases are listed with a protein data bank (PDB) code for a matching $x$-ray crystal structure. C. elegans and B. mori sulfotransferases are listed with their UniProt code. SULT_MOTIF indicates the residues which make up the cytosolic sulfotransferase amino acid sequence motif regions.

feeding in both larval and nymphal stages. During the adult tick feeding, there was no significant difference in SULT 1 or SULT 2 transcript abundance (unfed salivary gland: $3120 \pm 310$; fed salivary gland: $3510 \pm 260$; unfed midgut: $3350 \pm 320$; fed midgut: $3620 \pm 310$, copy number/reaction respectively).

Similar results were observed at the protein level using Western blot probed with antibodies raised against expressed and affinity-purified Ixosc Sult 1 or Sult 2. Band intensities were quantified using Kodak Digital Science 1D Image Analysis Software and plotted against different tick stages (Figure 3A and 3B; Figure 4A and 4B). Values are expressed as mean $\pm \mathrm{SD}$ for three replicated experiments and show significant differences between blood-fed and unfed states, respectively, at both the nymphal and larval stages. Similar to the quantitative PCR results, the Ixosc Sult 1 and 2 protein levels in the adult stage showed no difference on feeding (data not shown).

Full length Ixosc SULT 1 and SULT 2 were cloned into the pTrcHis2 TOPO TA expression vector. The expressed proteins were purified using a HIS-Select ILAP (Sigma) column. The purified Ixosc Sult 1(R) and Sult 2(R) showed molecular weights of 36 and $38 \mathrm{kDa}$, respectively (Figure $5 \mathrm{~A} \& 5 \mathrm{~B}$ ), and the purified proteins were sequenced using liquid automatic sequencing. The resulting sequences from the Expert Protein Analysis System (ExPASy) confirmed that the expressed proteins are from tick sulfotransferase genes (data not shown).

\section{Enzymatic characterization of Ixosc Sult 1 (R) and Sult 2} (R)

We tested whether expressed purified Ixosc Sult 1 (R) or Sult 2 (R) could sulfonate selected potentially relevant substrates. The rationale for including p-nitrophenol, $17 \mathrm{~b}$-estradiol, pregnenolone, and dopamine was that they are prototype substrates for the mammalian sulfotransferases. The rationale for including octopamine and an additional rationale for including dopamine was based on the relevance of these compounds as arthropod neuromodulators and on the previous structure modelling study [26] which predicted these monoamines as potential substrates for the I. scapularis sulfotransferases. Arthropod steroids such as ecdysone were not tested as substrates, as the previous structure modelling study indicated that these steroid structures are not complimentary to the binding pocket of the I. scapularis sulfotransferases and should not be substrates [26]. Each potential substrate was added to $4 \mu \mathrm{M} \mathrm{PAP}^{35} \mathrm{~S}$ (in water) and purified enzyme $(0.03-0.04 \mathrm{mg} / \mathrm{mL}$ in 20 $\mathrm{mM}$ potassium phosphate $\mathrm{pH}$ 7.0), and was incubated at $37^{\circ} \mathrm{C}$. Because of the zwitterionic nature of two of the expected products (dopamine-sulfate, octopamine-sulfate) at acidic $\mathrm{pH}$, we used cellulose thin-layer chromatography under strongly basic conditions for the separation. As shown in Figure 6 and quantified in Table 1, $p$-nitrophenol, dopamine, and $R, S$-octopamine were substrates for both Ixosc Sult 1 (R) and Sult 2 (R). 


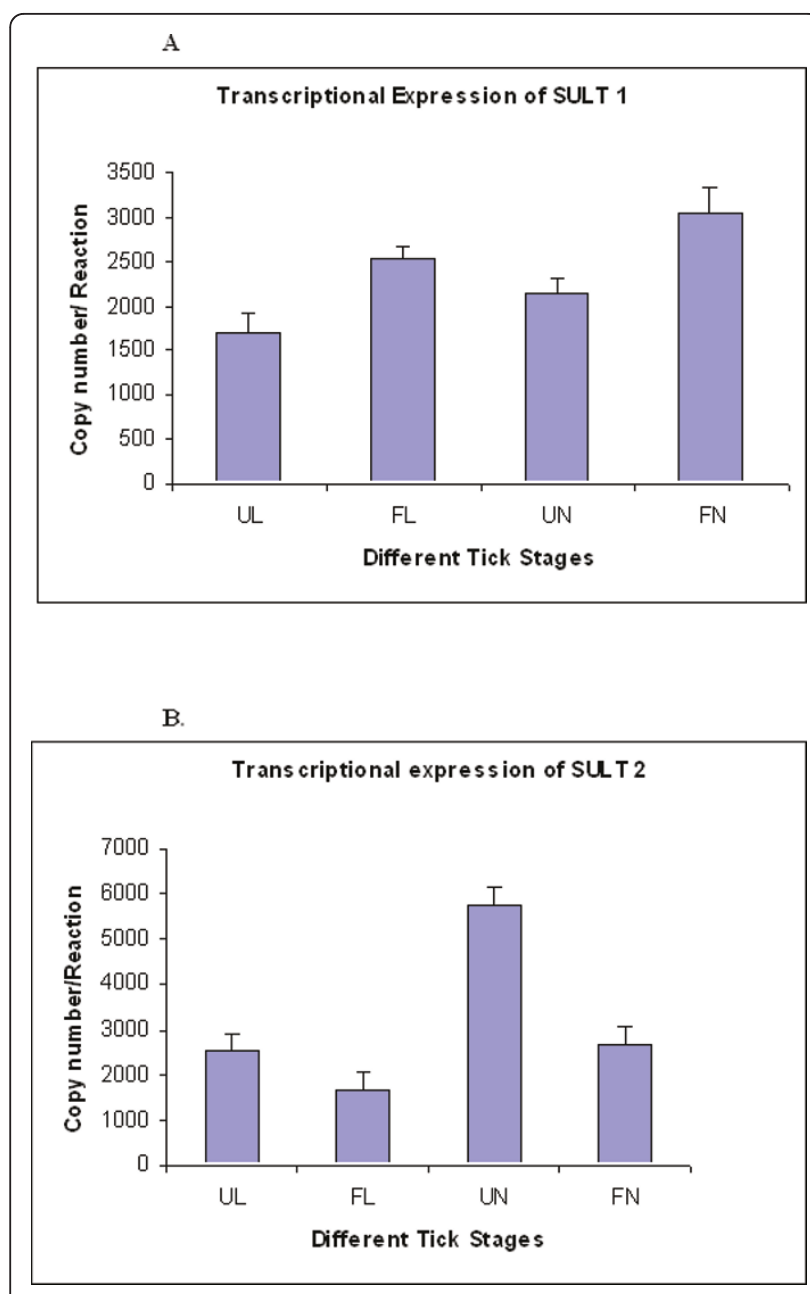

Figure 2 Quantitative analysis of IxOSC SULT 1 and SULT 2 mRNA Expression. Total RNA was extracted from different developmental stages and PCR amplified with gene specific primers. Quantitative transcriptional expression was determined as described in Materials and Methods. The PCR rates of SULT 1 (A) and SULT 2 $(B)$, in various stages of the tick life cycle were normalized to the rate of synthesis of $\beta$-actin, included as the endogenous control. Data were plotted as copy numbers per reaction to samples at various level of feeding. Bars indicate PCR values as the Mean \pm SD of three replicated experiments. Abbreviations: UL - Unfed Larvae, FL - Fed Larvae, UN - Unfed Nymph, FN - Fed Nymph.

The enzyme activity of expressed Ixosc Sult 1 (R) was found to be 1.3-1.5 nmol min ${ }^{-1} \mathrm{mg}^{-1}$ and Ixosc Sult 2 (R) to be $0.3-0.4 \mathrm{nmol} \mathrm{min}{ }^{-1} \mathrm{mg}^{-1}$, respectively, when incubated with $10 \mu \mathrm{M}$ of each potential substrate. Product formation in the absence of enzyme $\left(\mathrm{PAP}^{35} \mathrm{~S}\right.$ plus substrate) was found to be zero. $17 \beta$-estradiol and pregnenolone showed no product formation under the conditions tested (data not shown). Because the ${ }^{35} \mathrm{~S}$-labeled products of dopamine, octopamine, and $p$-nitrophenol migrated with a similar retention factor $\left(\mathrm{R}_{f}\right)$, their individual formation was confirmed by mass spectral analysis. The sulfated product of dopamine and octopamine,

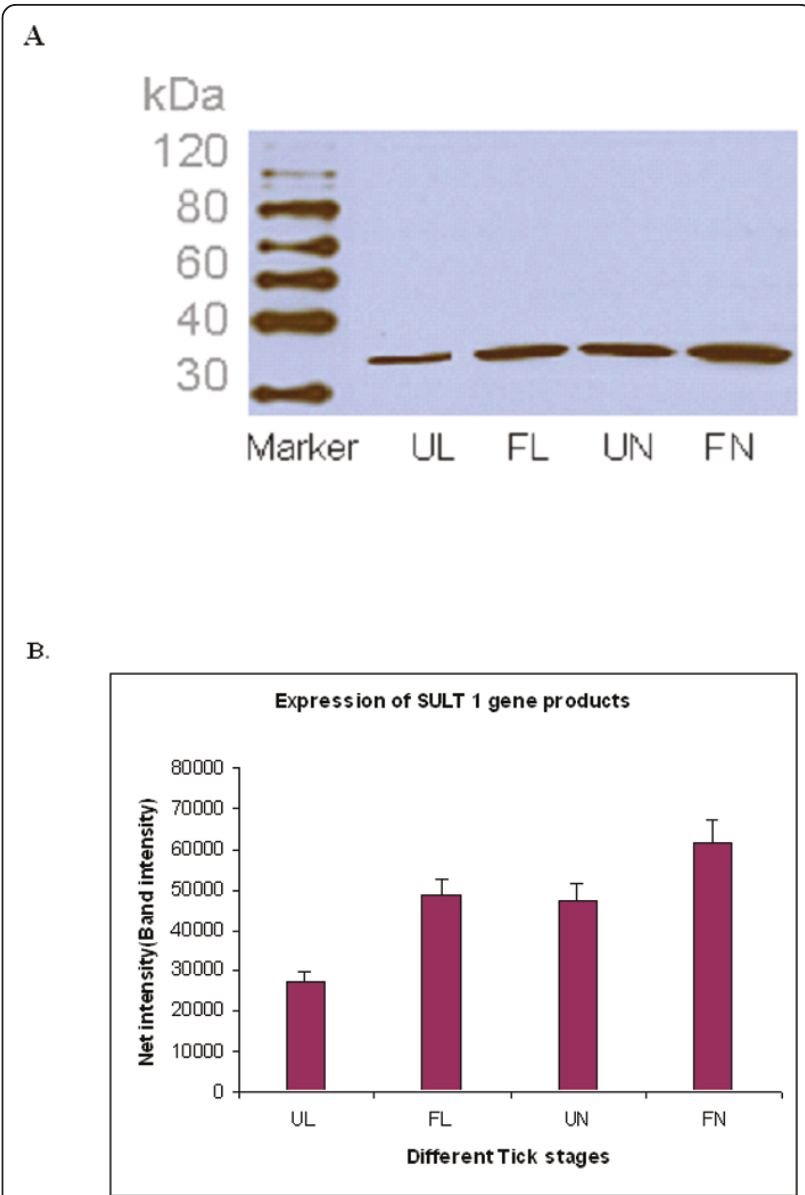

Figure 3 Analysis of Ixosc Sult 1 protein expression during feeding. (A) Ixosc Sult 1 detected by Western blot, (B) Quantitation of band intensity. Tissue homogenates from different developmental stages were analyzed by Western blot using anti-Sult 1 (R) raised antibody. Lanes: 1. Magic Marker, 2. Unfed larvae, 3. Fed larvae, 4. Unfed nymph, 5. Fed nymph. SULT 1 gene products were quantified using Kodak Digital Science 1D image analysis software and the net intensity/band intensity was plotted against the different tick stages.

respectively, were positively identified by mass spectral detection under negative ionization conditions ([dopamine- $\mathrm{SO}_{3}-\mathrm{H}^{+}+\mathrm{Na}^{+}$], $255.2 \mathrm{~m} / z$; [octopamine- $\mathrm{SO}_{3}-\mathrm{H}$ ${ }^{+}+\mathrm{Na}^{+}$], $255.2 \mathrm{~m} / z$ ) (Figure $\left.7 \mathrm{~A}, \mathrm{~B}, \mathrm{C}, \mathrm{D}, \mathrm{E}, \mathrm{F}\right) \cdot p$-Nitrophenylsulfate ion was detected in parallel incubations with both Ixosc Sult 1 and 2 (R) ([p-nitrophenol- $\mathrm{SO}_{3}$ $\mathrm{H}^{+}$], $217.9 \mathrm{~m} / \mathrm{z}$ ] Additional file 1. Kinetics of the native blacklegged tick sulfotransferases for dopamine and octopamine were recently published separately [26].

\section{Discussion}

In this study, we describe the expression of novel Ixodes scapularis sulfotransferase genes throughout the blacklegged tick life cycle and different states of blood feeding, and characterize their expressed recombinant 


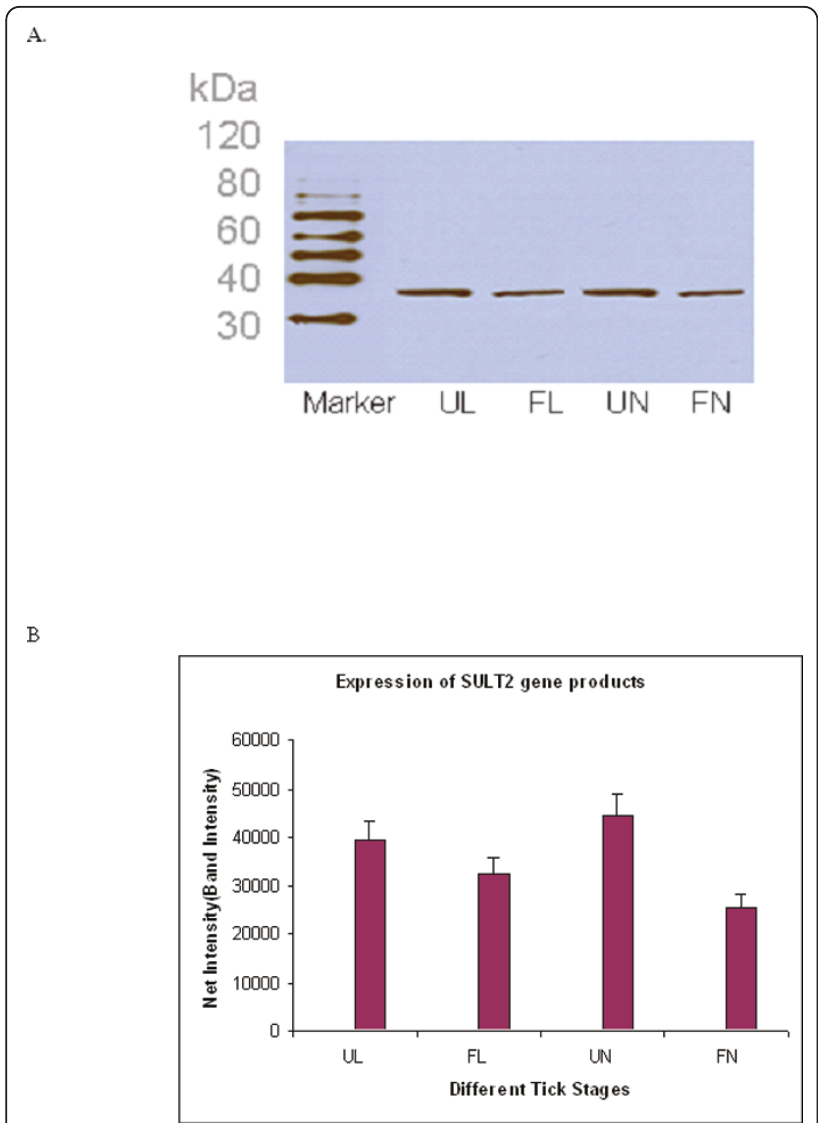

Figure 4 Analysis of Ixosc Sult 2 protein expression during feeding. (A) Ixosc Sult 2 detected by Western blot, (B) Quantitation of band intensity. Tissue homogenates from different

developmental stages were analyzed by Western blot using anti-Sult 2 (R) raised antibody. Lanes: 1. Magic Marker, 2. Unfed larvae, 3. Fed larvae, 4. Unfed nymph, 5. Fed nymph. SULT 2 gene products were quantified using Kodak Digital Science 1D image analysis software and the net intensity/band intensity was plotted against the different tick stages.

proteins. Ixosc Sult 1 and Sult 2 are expressed during every life stage of blacklegged ticks, and interestingly, mRNA and protein levels are moderately but significantly changed (1.5 - 2.6 fold) upon blood-feeding at the nymphal and larval stages. We find it especially interesting that the process of feeding has an opposite effect on relative expression of the Ixosc Sult 1 and Sult 2 during both the larval and nymphal life stages, although no change in expression levels could be detected in the adult stage salivary gland or midgut (Figures 2, 3, 4). Thus, these two proteins seem to have different roles in the tick salivation and feeding process. Ixosc SULT 1 mRNA and protein were increased upon feeding from a low basal level at the larval and nymphal stage. In contrast, Ixosc SULT 2 mRNA and protein were decreased upon feeding from a high basal level at the larval and nymphal stage. Quantitative RT-PCR and quantification

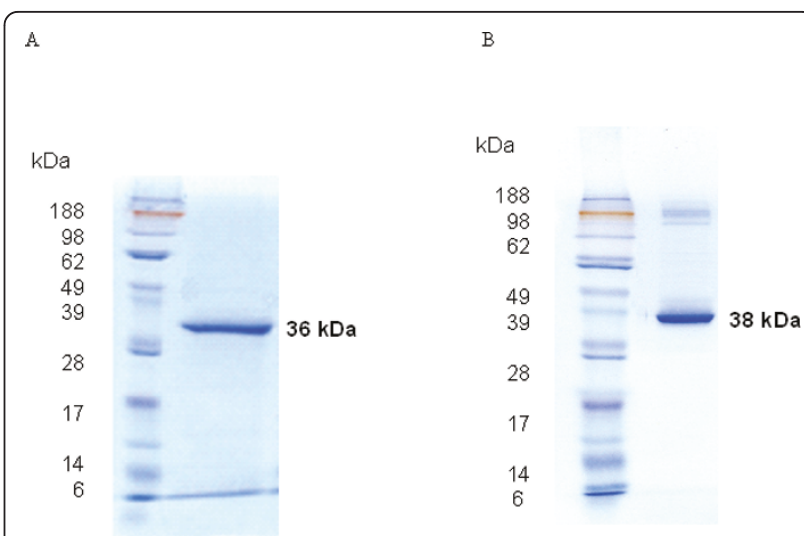

Figure 5 SDS-PAGE of expressed Ixosc Sult 1 (R) (A), Sult 2 (R) (B). The expressed purified recombinant proteins were analyzed and stained with Coomassie brilliant blue. Lanes: 1. Prestained molecular weight marker, 2. Purified protein.

of band intensities by Kodak Digital Analyser confirmed the statistical increase of SULT 1 and decrease of SULT 2 as well as their gene products during feeding. Our recent publication [26] on homology modelling, molecular docking and enzyme kinetic studies of sulfotransferase activity from native tick tissues showed similar findings using specific tick homogenates. It should be noted that these results were obtained from three pools of tissue derived from multiple ticks, and that the blood-fed ticks were sampled after being attached to hosts for $48-72$ hours. Because tick salivation and secretion is a dynamic process throughout the multi-day feeding, experiments are in progress to profile the

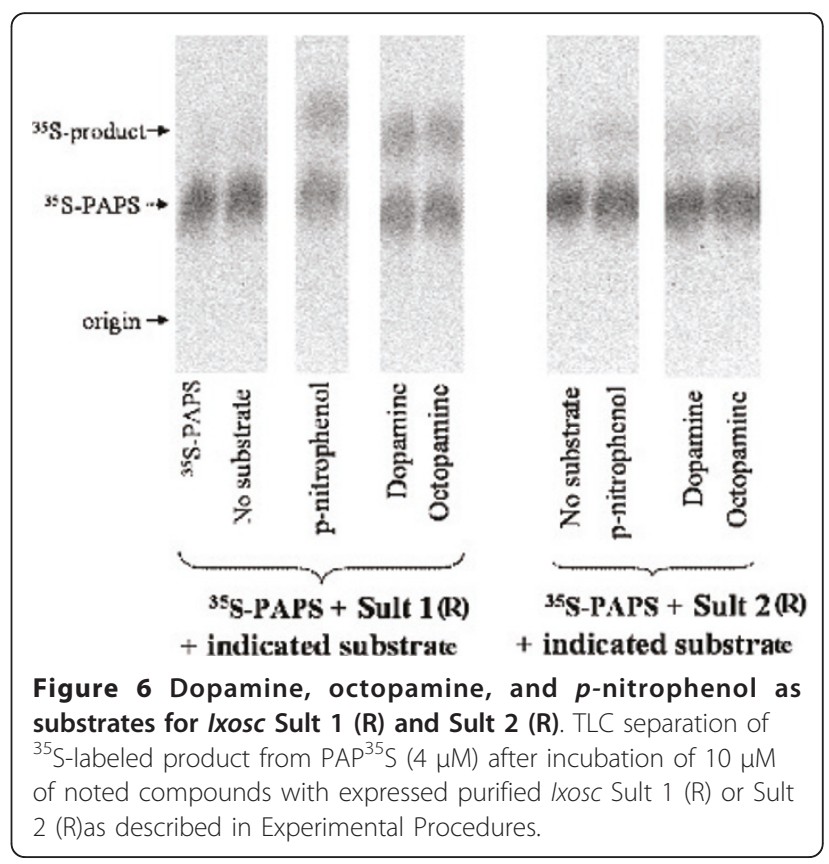


Table 1 Quantitation of Ixosc Sult 1 (R) and 2 (R) activity.

\begin{tabular}{ll}
\hline Reaction mixture & $\begin{array}{l}\text { Rate of reaction } \\
\left(\mathbf{n m o l ~} \mathbf{~ m i n}^{-1} \mathbf{~ m}^{-1}\right)\end{array}$ \\
\hline PAP ${ }^{35} \mathrm{~S}+$ Sult 1 (R) (Control) & 0.00 \\
p-Nitrophenol + Sult 1 (R) + PAP ${ }^{35} \mathrm{~S}$ & $1.30 \pm 0.01$ \\
Dopamine + Sult 1(R) + PAP ${ }^{35} \mathrm{~S}$ & $1.52 \pm 0.01$ \\
Octopamine + Sult 1(R) + PAP ${ }^{35} \mathrm{~S}$ & $1.34 \pm 0.01$ \\
PAP ${ }^{35}$ S + Sult 2 (R) (Control) & 0.00 \\
p-Nitrophenol + Sult 2 (R) + PAP ${ }^{35} \mathrm{~S}$ & $0.43 \pm 0.01$ \\
Dopamine + Sult 2 (R) + PAP ${ }^{35} \mathrm{~S}$ & $0.39 \pm 0.01$ \\
Octopamine + Sult 2 (R) + PAP ${ }^{35} \mathrm{~S}$ & $0.35 \pm 0.01$ \\
\hline
\end{tabular}

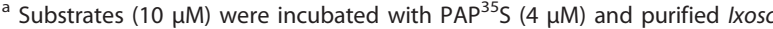
Sult $1(R)(0.04 \mathrm{mg} / \mathrm{mL})$ or Ixosc Sult $2(R)(0.03 \mathrm{mg} / \mathrm{mL})$ for $30 \mathrm{~min}$. Product formation in the absence of enzyme (PAP ${ }^{35} \mathrm{~S}+$ substrate) was found to be zero.

expression during more exact time periods. While there is evidence for altered expression of multiple genes during tick feeding [31], surprisingly little is known about the mechanism of gene expression in tick salivary glands. Furthermore, the exact tissue localization of the sulfotransferases in the nymphal and larval stage has not yet been determined; whole homogenates were used of unfed and blood-fed ticks at these life stages.

The related sulfotransferase (ceST) isolated from C. elegans catalyzed sulfonation of a variety of phenols at the rate of 0.1-0.5 nmol min ${ }^{-1} \mathrm{mg}^{-1}$, but no endogenous substrate was identified [10]. The sulfotransferase (bmST) isolated from Bombyx mori was found to catalyze sulfonation of 4-nitrocatechol at $0.2 \mathrm{nmol} \mathrm{min}{ }^{-1} \mathrm{mg}^{-1}$, although no endogenous substrate was identified [11]. The cytosolic sulfotransferases from $D$. melanogaster catalyzed sulfonation of vanillin, 1-naphthol, $p$-nitrophenol, ecdysone, and dopamine [13] at rates of 0.2-1 $\mu \mathrm{mol} \mathrm{min}^{-1}$ $\mathrm{mg}^{-1}$. The published rates of sulfonation by bmST and ceST are similar to those measured for Ixosc Sult 1 and 2.

The well-characterized human sulfotransferases catalyze sulfonation of a variety of endogenous hormones and neurotransmitters, as well as dietary phenols and environmental contaminants. In general, the sulfotransferases responsible for sulfonating endogenous substrates have high affinity for these substrates. Human SULT1A3, which is also called dopamine sulfotransferase, has a $\mathrm{Km}$ of $4 \mu \mathrm{M}$ for dopamine, while human SULT1A, generally called phenol sulfotransferase, has a Km of $130 \mu \mathrm{M}$ for dopamine. Human SULT1E1, which is also called estrogen sulfotransferase, has a Km of 1-20 nM for 17 $\beta$-estradiol, while human SULT1A1 and SULT2A1 can sulfonate $17 \beta$-estradiol with $\mathrm{Km}$ of 1-30 $\mu \mathrm{M}$. In our earlier findings, dopamine was found to be a good substrate $(\mathrm{Km}$ of 0.1-0.4 $\mu \mathrm{M})$ for the native tick sulfotransferases irrespective of their feeding stage where as octopamine served as a substrate only after feeding [26].
Interestingly, in this present study, we found that both dopamine and $R, S$-octopamine could serve as substrates for purified Ixosc Sult 1 (R) and Sult 2 (R) at a concentration of $10 \mu \mathrm{M}$. We chose $10 \mu \mathrm{M}$ as a test concentration because of our detection method's limit of sensitivity. Further studies are needed to explore the physiological relevance of Ixosc Sult 1 and Sult 2 sulfonation of tick neuroeffectors dopamine and octopamine, and to identify possible additional sulfotransferases in Ixodes scapularis.

We find the sulfonation of dopamine and octopamine to be noteworthy because salivary secretion in feeding ticks is under neuronal control. Tick salivary gland secretion is stimulated by dopamine in the neuroeffector junction via dopamine D1 receptor activation of adenylate cyclase and an increase in intracellular cAMP $[27,32]$. Dopamine also opens a voltage-gated $\mathrm{Ca}^{2+}$ channel allowing an influx of extracellular calcium that stimulates a cytosolic phospholipase A2, effecting release of sequestered arachidonic acid in tick salivary glands that is subsequently converted to prostaglandins [33]. Prostaglandins are secreted at extremely high $(\mu \mathrm{M})$ levels into tick saliva for export to the host [27] where they exhibit anti-hemostatic, vasodilatory, immuno-suppressive, and anti-inflammatory activities [34-36]. Thus, dopamine could modulate salivation and/or prostaglandin production in the tick salivary gland. Octopamine acts as a neuromodulator in arthropods with a similar mechanism to dopamine [30]. In insects, octopaminergic neurons modulate a variety of target tissues, which include skeletal muscles, heart and oviduct [37]. However, the exact tissue localization of the sulfotransferases in nymphal and larval blacklegged ticks has not yet been determined; whole homogenates were used of unfed and blood-fed ticks at these life stages.

In contrast to vertebrates, invertebrates use a variety of enzymatic routes to metabolise monoamines. These routes include sulfonation, $\mathrm{N}$-acetylation, gamma-glutamyl conjugation, sugar conjugation, $\beta$-alanyl conjugation, as well as oxidative deamination [38]. Catabolism is one of the effective mechanisms for dopamine inactivation. In humans, this involves multiple pathways that include oxidative deamination by monoamine oxidase (MAO), O-methylation by catechol-O-methyltransferase (COMT) and conjugation by sulfotransferase [39]. Regarding ticks, reports from Atkinson et al. [40] confirm the presence of monoamine oxidase (MAO) in the homogenates of B. microplus larvae, and MAO inhibition potentiated the dopamine effect on fluid secretion from salivary glands of $A$. hebraeum in vitro [41,42]. According to in vivo experiments by Kaufman and Sloley [42], it is clear that MAO is not the only means for disposing of biogenic amines in ticks. Octopamine $\mathrm{N}$ acetyltransferase (with a $\mathrm{Km}$ for octopamine of $4 \mu \mathrm{M}$ ) 

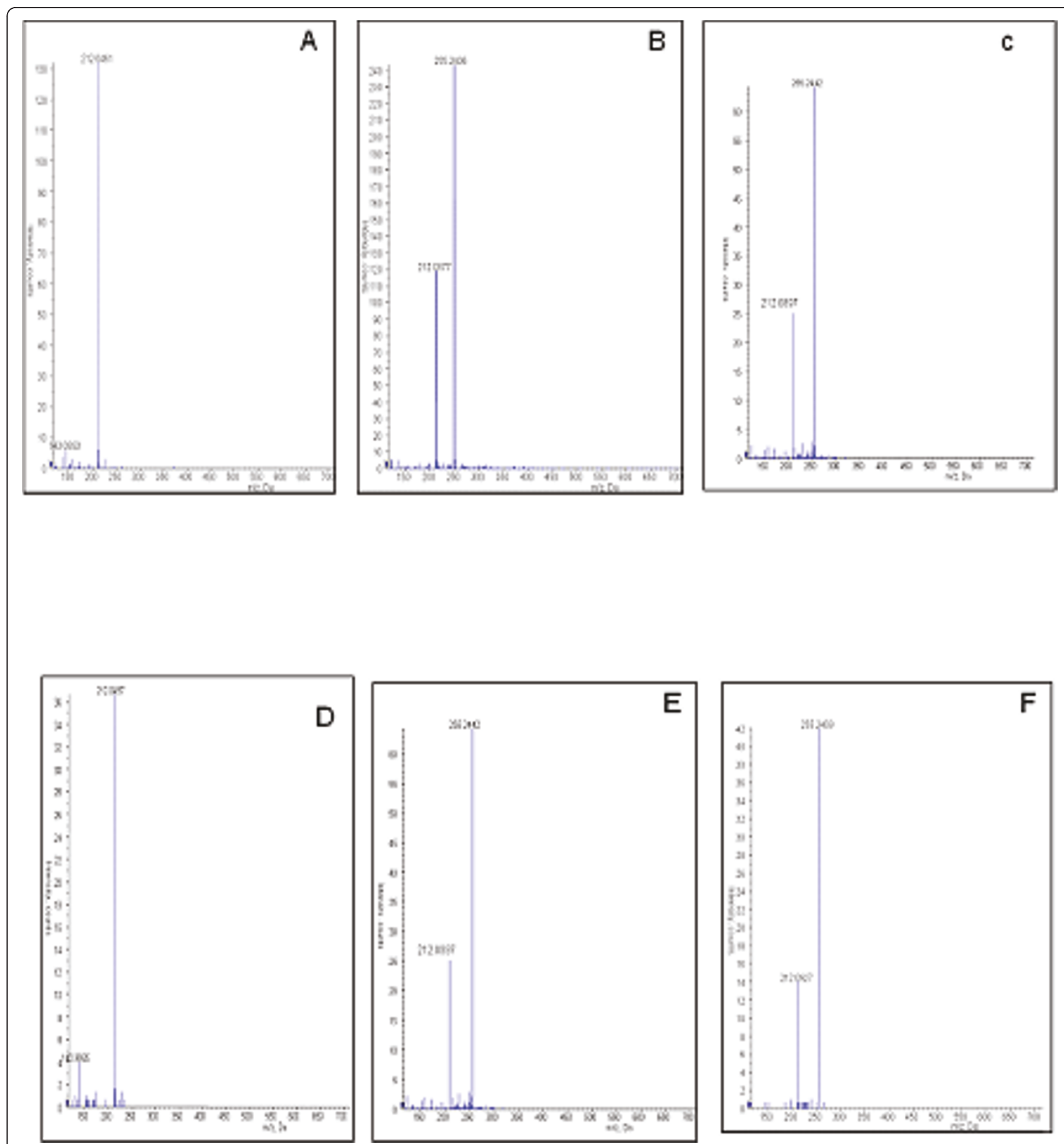

Figure 7 Mass Spectra of dopamine-sulfate and octopamine-sulfate formed by incubating Ixosc Sult 1(R) or Ixosc Sult 2 (R). A: Sult 1 (R) with PAP ${ }^{35}$ S (Control), B: Sult 1(R) + PAP ${ }^{35}$ S + Dopamine, C: Sult 1 (R) + PAP ${ }^{35}$ S + Octopamine, D: Sult 2 (R) + PAP ${ }^{35}$ S (Control), E: Sult 2 (R) + $P A P^{35} S+$ Dopamine, $\mathbf{F}$ : Sult $2(R)+P A P^{35} S+$ Octopamine.

has been demonstrated in the synganglion of B. microplus [43]. Thus, multiple pathways may be available for inactivating monoamines in tick species. Indeed, despite the recent advances in tick neurobiology and the identification of key genes, tick neuroscience lags behind that other invertebrates [44].
Ixosc Sult 1 or Sult 2 may serve as critical modulators of the prostaglandin synthesis pathway or as modulators of salivary secretion. Because all neuronally released biogenic amines have relatively short half-lives to prevent their action from continuing after the neuronal signal arrests, we thus propose that the two tick sulfotransferases 
described herein could function by metabolically altering the biological signal for salivary secretion in I. scapularis even though both of these genes were expressed differently. We are currently following up on these studies to explore their physiological relevance to tick feeding.

\section{Conclusions}

The salivary glands of ticks, in addition to their role in feeding, serve a role in ion and water metabolism. In a blood-feeding tick, production of saliva is the main mechanism of water excretion, ie. ticks alternate blood ingestion and salivation. Therefore, interrupted or inappropriate sulfation of neurotransmitter molecules involved in salivation could negatively affect a tick's ability to alternate the cyclic salivation and blood sucking process, potentially inhibiting blood feeding and pathogen transmission. In this study, we observed that expression of Ixosc Sult 1 is up-regulated, while expression of Ixosc Sult 2 is down-regulated during blood feeding at both the larval and nymphal stages, suggesting that these sulfotransferases have different functions in the salivation/feeding process of blacklegged ticks, even though expressed recombinant proteins sulfonate both dopamine and octopamine. Further experiments, perhaps using sulfotransferase gene knockdown in these ticks may help clarify the significance of our observations.

\section{Methods}

\section{Reagents}

Restriction enzymes, Taq DNA polymerase, Plasmid DNA and polymerase chain reaction (PCR) product purification kits, Block-iT T7 TOPO linker were purchased from Invitrogen (Carlsbad, CA, USA) and Qiagen (Valencia, CA, USA). Mouse IgG-HRP was purchased from StressGen (Victoria, BC, Canada). The prokaryotic expression vector pTrc His2 Topo TA was purchased from Invitrogen, CA, USA. Enzyme chemiluminescent detection system was obtained from KPL laboratories. $\left[{ }^{35} \mathrm{~S}\right]-3$ '-phosphoadenosine-5' - phosphosulfate (PAP $\left.{ }^{35} \mathrm{~S}\right)$ was purchased from Perkin Elmer Life and Analytical Sciences $(1.1-2.43 \mathrm{Ci} / \mathrm{mmol}$, solution in $1: 1$ ethanol: water). Unlabeled PAPS was purchased from Sigma Chemical and was purified before use by HPLC separation.

\section{Amino acid sequence comparisons}

The Ixosc Sult 1 and Sult 2 sequences were compared with a set of known cytosolic sulfotransferase family. Multiple sequence comparisons were conducted using Accelrys SeqLab (GCG version 11.1). Human sulfotransferases are listed with a protein data bank code for a matching x-ray crystal structure. C. elegans and B. mori sulfotransferases are listed with their UniProt code.

\section{Tick collection and feeding}

Ixodes scapularis ticks collected as unfed adults from forests in southern Rhode Island were allowed to blood feed on New Zealand white rabbits under controlled laboratory conditions [45]. A restraining collar was placed around the neck of each rabbit, and their ears were covered with cotton socks prior to tick exposure. These engorged adult ticks laid eggs, and hatched larvae were reared in the laboratory by blood feeding on golden hamsters to produce nymphs. To produce partially engorged experimental ticks, larvae and nymphs were allowed to feed on mice and adult ticks fed on New Zealand white rabbits [45]. The length of feeding of the larvae and nymphs was 48-72 hr, and the feeding time of the adults was $72 \mathrm{hr}$. All animal studies were approved by the Institutional Animal Care and Use Committee (protocol number AN01-12-014).

\section{Tick tissue samples}

Three pooled samples from eggs, larvae and nymphs ( 30 - 50) were homogenized and used for the studies. Three tissue pools from salivary gland or midguts were dissected from adult ticks ( 30 adults). Adult tick salivary gland or midgut tissue was dissected in ice-cold $100 \mathrm{mM}$ 3-(N-morpholino)-propanesulfonic acid (MOPS) buffer containing 20 mM EGTA, pH 6.8. When used for isolating total RNA, tissues were washed gently in MOPS/EGTA buffer and immediately stored in RNA later. For Western blotting, tick tissues were used immediately after being dissected or were stored at $-70^{\circ} \mathrm{C}$ in $0.5 \mathrm{M}$ piperazine-N,N-bis-2-ethane sulfonic acid, $\mathrm{pH}$ 6.8, containing $20 \mathrm{mM}$ EGTA, $1 \mathrm{X}$ Complete Mini-Protease $^{\mathrm{TM}}$ Inhibitor Cocktail (Roche) and 40\% glycerol (v/ v). All manipulations were carried out at $4^{\circ} \mathrm{C}$.

\section{Quantitative Expression of Ixosc SULT 1 and SULT 2 genes-qRT-PCR}

Gene specific primers [GenBank: DQ066225.1 and GenBank: DQ066226.1] of Ixosc SULT 1 and SULT 2 genes [5] were designed. Total RNA was isolated using an RNAqueous ${ }^{@}$ total RNA isolation kit (Ambion) from eggs, unfed larvae, unfed nymphs, unfed adults, 48-72 hr fed larvae, 48-72 hr fed nymphs, and $72 \mathrm{hr}$ fed adults. Concentration and purity of total RNA was determined spectrophotometrically at 260 and $280 \mathrm{~nm}$, aliquoted and stored at $-80^{\circ} \mathrm{C}$ until use.

Real-time quantitative PCR was performed using the Mx4000 or Mx3005P Multiplex Quantitative PCR system and the Brilliant SYBR Green Single Step QRTPCR Master Mix Kit (Stratagene, La Jolla, CA) according to the manufacturer's instructions. A standard curve of $10^{0}-10^{7}$ copies per reaction were generated using purified Ixosc SULT 1 and SULT 2 PCR products as the template. The following primers were used for all 
reactions: SULT 1 Forward 5'ACATGATCTGGGGCGACTAC3' and Reverse 5'GTCAAGGGTGCTCT CGTCTC3', SULT 2 Forward 5'GTTATGCTCTGCGACACGAA3' and Reverse 5'ACTCACGTCGAACG TCCTCT3'. Reactions contained 10 ng of RNA were run under the following conditions: 1 cycle of $50^{\circ} \mathrm{C}$ for $30 \mathrm{~min}$ and $90^{\circ} \mathrm{C}$ for $15 \mathrm{~min}$ followed by 40 cycles of $95^{\circ} \mathrm{C}$ for $30 \mathrm{~s}$ and $51^{\circ} \mathrm{C}$ for $30 \mathrm{~s}$. Fluorescence was measured every cycle at the end of the $51^{\circ} \mathrm{C}$ step. The copy number of SULT 1 and SULT 2 mRNA in each sample was determined using the Mx4000 or Mx3005P data analysis software based on the standard curve. The relative quantity of target mRNA in each sample was normalized to $\beta$-actin mRNA. All the reactions were done in triplicate.

\section{Cloning, sequencing and expression of Ixosc SULT 1 and Ixosc SULT 2 in E. Coli}

After PCR amplified full-length Ixosc SULT 1 and Ixosc SULT 2, gel-purified fragments were cloned into the pTrcHis2 TOPO TA expression vector. Standardized methods were followed to insert plasmid into Top10 E. coli (Invitrogen), and the proper insertion was confirmed. The pTrcHis2 TOPO TA expression vector contains an ampicillin resistance gene, IPTG promoter, and six-residue histidine tag. Expression was induced with IPTG treatment $(0.3 \mathrm{mM})$ for $3 \mathrm{hrs}$. Cells were treated with $0.3 \mathrm{mg} / \mathrm{mL}$ lysozyme for $30 \mathrm{~min}$, washed twice with homogenization buffer, and homogenized by sonication. Homogenization buffer consisted of $20 \mathrm{mM}$ potassium phosphate $\mathrm{pH} 7.0$ with $1 \mathrm{mM}$ dithiothreitol, and $1 \mathrm{mM}$ PMSF. Cytosolic fractions were isolated by preparation of $100,000 \times g$ supernatant. For purification of expressed Ixosc Sult 1 and Ixosc Sult 2, cytosol was loaded onto a HIS-Select ILAP (Sigma) immobilized metal affinity chromatography resin, and eluted with 50 $\mathrm{mM}$ imidazole and $500 \mathrm{mM} \mathrm{NaCl}$. Eluted protein was passed through the desalting column (Zeba Desalt Spin columns, Pierce, USA) to remove imidazole and sodium chloride before being used for enzyme assays. Protein purity was assessed using denaturing gel electrophoresis with Coomassie blue staining or Western blot detection. Hereafter the purified recombinant proteins were referred as Ixosc Sult 1 (R) and Sult 2 (R). The expressed enzyme was detected using Anti-His (C-term) antibody (Invitrogen, USA).

\section{Polyclonal antibody to expressed purified Ixosc Sult 1 (R) or Sult 2 (R)}

Expressed and purified Ixosc Sult 1 (R) and Sult 2 (R) were used separately to immunize BALB/c female mice (4 to 6 weeks old, Charles River, three mice per each purified protein). Mice were injected intra muscularly four times over six weeks (at two week intervals) with
$20 \mu \mathrm{g}$ of purified protein in each treatment. Antibody production was assessed by sampling venous blood and using it as probe for Western blots.

\section{Western blotting}

Pooled salivary glands, midgut or whole tissue (3 different pooled samples) from each tick life stage (unfed larvae, unfed nymph, unfed adult, 48-72 hr fed larvae, 48$72 \mathrm{hr}$ fed nymph, and $72 \mathrm{hr}$ fed adult) were homogenized (1 min sonication) in ice-cold extraction buffer (PBS, $1 \mathrm{mM}$ dithiothreitol, $2.5 \mathrm{mM}$ EGTA, and $1 \mathrm{X}$ Complete Mini-Protease ${ }^{\mathrm{TM}}$ Inhibitor Cocktail (Roche)). Additionally, affinity-purified Ixosc Sult 1 (R) and Sult 2 (R) were used as positive controls. Protein concentration was estimated by the Bradford method [46]. Tick salivary gland protein extracts (20-30 $\mu$ g each life stage or tissue) were separated by $10 \%$ SDS-polyacrylamide gel electrophoresis (SDS-PAGE) [47] and then transferred onto nitrocellulose membranes in a Transblot cell (BioRad) following the manufacturer's instructions [48]. Nonspecific protein binding sites were blocked with $5 \%$ skim milk, and the membranes were incubated with polyclonal Ixosc Sult 1 (R) or Ixosc Sult 2 (R) antibodies at a dilution of 1:2000. Antigen-antibody complexes were visualized with horseradish peroxidase-conjugated anti-mouse IgG (StressGen) at a dilution of 1:10,000 and detected with SuperSignal chemiluminescent peroxidase substrate (Pierce, Rockford, IL, USA) on a Bio-Rad ChemiDoc XRS imaging system. All reactions were done in triplicates. The net intensity/band intensity was quantified using Kodak digital 1D image analysis software.

\section{Sulfotransferase activity}

Ability of expressed Ixosc Sult 1(R) and Sult 2(R) to catalyze sulfonation of test chemicals was assessed using expressed purified enzyme preparations (in $20 \mathrm{mM}$ potassium phosphate $\mathrm{pH}$ 7.0) and $\mathrm{PAP}^{35} \mathrm{~S}$ (in water). For these assays, the ethanol: water solvent of the commercial $\mathrm{PAP}^{35} \mathrm{~S}$ was evaporated in vacuum and the residue reconstituted in water. Potential substrates (dopamine, $R, S$-octopamine, $p$-nitrophenol, $17 \beta$-estradiol and pregnenolone) were dissolved in water and diluted into the incubation mixture to the final concentration of $10 \mu \mathrm{M}$. Assays generally contained $0.03-0.08 \mathrm{mg} / \mathrm{mL}$ purified expressed protein and $0.01 \mathrm{mCi} / \mathrm{mL}(4-9 \mu \mathrm{M})$ $\mathrm{PAP}^{35} \mathrm{~S}$. After $30 \mathrm{~min}$ at $37^{\circ} \mathrm{C}$, reactions were stopped by heat inactivation and pelleting of denatured protein. Sulfated metabolites were identified by mass spectrometry as described below. For quantification, supernates were spotted onto the cellulose thin-layer chromatographic (TLC) paper, and components were separated by capillary movement of the mobile phase (2-propanol: ammonium hydroxide: water, 6:3:1) up the paper [49]. 
Radiolabeled components were visualized and quantified after phosphor transfer (Kodak TR storage phosphor screen \#9715) with subsequent phosphor imaging on a Typhoon 9410. All experiments were done with at least three replications.

The sulfated metabolites were identified by mass spectrometry on a QSTAR ${ }^{\circledR}$ Elite LC/MS/MS-TOF (Applied Biosystems, USA) in the negative ion mode. Incubation supernates were directly injected through a syringe filter $(0.45 \mu \mathrm{m})$ and ionized by turbo-electrospray. Ions were scanned over a region of $50-1000 \mathrm{~m} / \mathrm{z}$. Background scans were collected just before injection of sample. All experiments were done at least in triplicates.

\section{Statistical Analysis}

Where indicated, values were expressed as mean \pm SD of three determinations. Statistical differences were carried out by Sigma Stat version 3.5 (Systat Software Inc. San Jose, CA) student's t-test. $\mathrm{p}$ values of $<0.05$ were considered statistically significant.

\section{Additional material}

Additional file 1: Mass Spectra of $p$-nitrophenyl sulfate. Mass Spectra of p-nitrophenyl sulfate formed by incubating Ixosc Sult 1(R) or Ixosc Sult 2 (R). a) Sult $1(R)+P A P^{35} S+p$-nitrophenol, b) Sult $2(R)+P A P^{35} S+p-$ nitrophenol.

\begin{abstract}
Acknowledgements
We are particularly grateful to Nathan Miller, Drs. Marta Gomez-Chiarri, Wendy M. Coy, Shahid Karim and Assem Sayedahmed for helpful technical discussions. This work was supported in part by National Institute of Health grants RO1 Al 37230 and U19 Al 082642 (TNM), a subcontract to USDA Special Grant 2006-34438-17306 (TNM), and by the Division of Intramural Research, National Institute of Allergy and Infectious Diseases, NIH (JMCR). Experiments were supported by the URI Proteomics Core facility, made available by the RI-BRIN and RI-INBRE (NIH award P20 RR16457). Because JMCR is a government employee and this is a government work, the work is in the public domain in the United States. Notwithstanding any other agreements, the NIH reserves the right to provide the work to PubMedCentral for display and use by the public, and PubMedCentral may tag or modify the work consistent with its customary practices. You can establish rights outside of the U.S. subject to a government use license. It is contribution number 5133 of the Rhode Island Agricultural Experiment Station.
\end{abstract}

\section{Author details}

${ }^{1}$ Center for Vector-Borne Disease, University of Rhode Island, Kingston, RI 02881, USA. Department of Biomedical and Pharmaceutical Sciences, College of Pharmacy, University of Rhode Island, Kingston, RI, 02881, USA. ${ }^{3}$ Section of Vector Biology, Laboratory of Malaria and Vector Research, National Institute of Allergy and Infectious Diseases, National Institutes of Health, Bethesda, Maryland, 20892, USA.

\section{Authors' contributions}

SP carried out the molecular genetic studies, design and executed the experiments and drafted the manuscript. EBY carried out the sulfotransferase assays and analyses. JMCR was involved in part of the experimental design and in critically revising the final manuscript. RSK was involved in the experimental design, experiment coordination, and in critically revising the manuscript. TNM was involved in the experimental design, experiment coordination, and in critically revising the manuscript. All authors have approved the final manuscript.

Received: 11 January 2011 Accepted: 27 June 2011

Published: 27 June 2011

\section{References}

1. Balashov YS: Bloodsucking ticks (Ixodoidea), vectors of disease of man and animals. Miscellaneous Publications of the Entomological Society of America 1972, 8:163-376.

2. Sonenshine D: Biology of ticks. Oxford University Press, New York; 19932.

3. Wikel SK: Tick modulation of host immunity: an important factor in pathogen transmission. Int J Parasitol 1999, 29:851-85.

4. Francischetti IV, Sa-Nunes A, Mans BJ, Santos IM, Ribeiro JMC: The role of saliva in tick feeding. Frontiers in Bioscience 2009, 14:2051-2088.

5. Ribeiro JMC, AlarconChaidez F, Francischetti IMB, Mans BJ, Mather TN, Valenzuela JG, Wikel SK: An annotated catalog of salivary gland transcripts from Ixodes Scapularis ticks. Insect Biochemistry and Molecular Biology 2006, 36:111-129.

6. Chapman E, Best MD, Hanson SR, Wong CH: Sulfotransferases: structure, mechanism, biological activity, inhibition, and synthetic utility. Angew Chem Int Ed Engl 2004, 43(27):3526-48.

7. Gamage N, Barnett A, Hempel N, Duggleby RG, Windmill KF, Martin JL, McManus ME: Human sulfotransferases and their role in chemical metabolism. Toxicol Sci 2006, 90(1):5-22

8. Kauffman FC: Sulfonation in pharmacology and toxicology. Drug Metab Rev 2004, 36(3-4):823-43.

9. Strott CA: Sulfonation and molecular action. Endocrine Reviews 2002, 23:703-732.

10. Hattori $K$, Inoue $M$, Inous $T$, Arai $H$, Tamura H: A novel sulfotransferase abundantly expressed in the Dauer Larvae of Caenorhabditis elegans. J Biochem 2006, 139:355-362.

11. Hattori KH, Hirayama M, Suzuki H, Hammoto H, Sekimizu K, Tamura HO: Cloning and expression of a novel sulfotransferase with unique substrate specificity from Bombyx mori. Biosci Biotechnol Biochem 2007, 71(4):1044-1051.

12. Grun F, Noy N, Hammerling U, Buck J: Purification, cloning, and bacterial expression of retinol dehydratase from Spodoptera frugiperda. J Biol Chem 1996, 271:16135-16138.

13. Hattori K, Motohashi N, Kobayashi I, Tohya T, Oikawa M, Tamura H: Cloning, Expression, and characterization of cytosolic sulfotransferase Isozymes from Drosophila Melanogaster. Biosci Biotechnol Biochem 2008, 72(2):540-547.

14. Liu T, Liu MC, Yang YS: Immunohistochemical analysis of a novel dehydroepiandrosterone sulfotransferase-like protein in Drosophila neural circuits. Biochem and Biophys Res Com 2008, 367:14-20.

15. Kinnunen T, Huang Z, Townsend J, Gatdula MM, Brown JR, Esko JD, Turnbull JE: Heparan 2-O-sulfotransferase, hst-2, is essential for normal cell migration in Caenorhabditis elegans. Proc Natl Acad Sci USA 2005, 102:1507-1512.

16. Ouyang YB, Moore KL: Molecular cloning and expression of human and mouse tyrosylprotein sulfotransferase-2 and a tyrosylprotein sulfotransferase homologue in Caenorhabditis elegans. J Biol Chem 1998 273:24770-24774.

17. Kasinathan C, Ramaprasad P, Sundaram R: Identification and characterization of tyrosylprotein sulfotransferase from human saliva. Int J Biol Sci 2005, 1:141-145.

18. Murty VL, Bilski J, Liau YH, Slomiany A, Slomiany BL: Sulfation in vitro of mucus glycoprotein by submandibular salivary gland: Effects of prostaglandin and acetylsalicylic acid. Biochim Biophys Acta 1988, 966(3):287-96

19. Kasinathan C, Sundaram R, William S: Effect of prostaglandins on tyrosylprotein sulfotransferase activity in rat submandibular salivary glands. Gen Pharmac 1995, 26:577-580.

20. William S, Ramaprasad P, Kasinathan C: Purification of tyrosylprotein sulfotransferase from rat submandibular salivary glands. Arch Biochem Biophys 1997, 338:90-96.

21. Gibbs TT, Russek SJ, Farb DH: Sulfated steroids as endogenous neuromodulators. Pharmacol, Biochem \& Behavior 2006, 84:555-567.

22. Liu J, Pedersen LC: Anticoagulant heparan sulfate: structural specificity and biosynthesis. Appl Microbiol Biotechnol 2007, 74(2):263-72. 
23. Druker J, Liberman AC, Acuna M, Giacomini D, Refojo D, Silberstein S, Pereda MP, Stalla GK, Holsboer F, Artz E: Molecular understanding of cytokine-steroid hormone dialogue. Ann NY Acad Sci 2006, 1088:297-306.

24. Moore KL: The biology and enzymology of protein tyrosine O-sulfation. $J$ Biol Chem 2003, 278(27):24243-6.

25. Niehrs C, Huttner WB, Carvallo D, Degryse E: Conversion of recombinant hirudin to the natural form by in vitro tyrosine sulfation. $J$ Biol Chem 1990, 265:9314-9318.

26. Yalcin EB, Stangl H, Pichu S, Mather TN, King RS: Monoamine neurotransmitters as substrates for novel tick sulfotransferases, homology modelling, molecular docking and enzyme kinetics. ACS Chem Biol 2011, 6(2):176-84, Epub 2010 Nov 15.

27. Sauer JR, Essenberg RC, Bowman AS: Salivary glands in Ixodid ticks: control and mechanism of secretion. J Insect Physiology 2000, 46:1069-1078

28. Binnington KC, Stone BF: Distribution of catcholamines in the cattle tick Boophilus microplus. Comp Biochem Physiol 1977, 58C:21-28.

29. Binnington $\mathrm{KC}$, Kemp DH: Role of tick salivary glands in feeding and disease transmission. Adv Parasitol 1980, 18:315-319.

30. Pannabecker T, Needham GR: Effects of octopamine on fluid secretion by isolated salivary glands of a feeding ixodid ticks. Archives of Insect Biochemistry and Physiology 1984, 2(2):217-226.

31. Narasimhan S, DePonte K, Marcantonio N, Liang X, Royce TE, Nelson KF, Booth CJ, Koski B, Anderson JF, Kantor F, Fikrig E: Immunity against Ixodes scapularis Salivary Proteins expressed within 24 Hours of Attachment Thwarts Tick Feeding and Impairs Borrelia Transmission. PLOS ONE 2007, 2(5):e451.

32. Bodnaryk RP: Basal, dopamine- and octopamine-stimulated adenylate cyclase activity in the brain of the moth, $M$ amestra configurat. A J Neurochem 1979, 33(1):275-82.

33. Aljamali MN, Bowman AS, Dillwith JW, Tucker JS, Yates GW, Essenberg RC, Sauer JR: Identity and synthesis of prostaglandins in the lone star tick, Amblyomma americanum (L.), as assessed by radio-immunoassay and gas chromatography/mass spectrometry. Insect Biochem Mol Biol 2002, 32:331-341.

34. Ribeiro JMC, Evans PM, MCSwain JL, Sauer JR: Ambylomma americanam: characterization of salivary prostaglandins E2 and F2 alpha by RP-HPLC/ bioassay and gas chromatography-mass spectrometry. Exp Parasitol 1992, 74:112-116.

35. Bowman AS, Dillwith JW, Sauer JR: Tick salivary prostaglandins: presence, origin and significance. Parasitol Today 1996, 12:388-396.

36. Sa-Nunes A, Bafica A, Lucas DA, Conrads TP, Veenstra TD, Andersen JF, Mather TN, Ribeiro JM, Francischetti IM: Prostaglandin E2 is a major inhibitor of dendritic cell maturation and function in Ixodes scapularis saliva. J Immunol 2007, 79:1497-505.

37. Evans PD: Biogenic amines in the insect nervous system. In Advances in Insect Physiology. Volume 15. Edited by: Berridge MJ, Treherne JE, Wigglesworth VB. London: Academic Press; 1980:317-473.

38. Sloley BD: Metabolism of monoamines in Invertebrates: The relative importance of monoamine oxidase in different phyla. Neurotoxicology 2004, 25:175-183.

39. Ben-Jonathan N, Hnasko R: Dopamine as a Prolactin (PRL) Inhibitor. Endocrine Reviews 2001, 22(6):724-763.

40. Atkinson PW, Binnington KC, Roulston WJ: High monoamine oxidase activity in the tick, Boophilus microplus and inhibition by chlordimeform and related pesticides. J Austral Entomol Soc 1974, 13:207-210.

41. Wong DLP, Kaufman WR: Potentiation by spiperone and other butyrophenones of fluid secretion by isolated salivary glands of Ixodid ticks. Eur J Pharmac 1981, 73:163-173.

42. Kaufman R, Sloley BD: Catabolism of Dopamine and 5-Hydroxytryptamine by Monoamine Oxidase in the Ixodid tick, Amblyomma hebraeum. Insect Biochem Molec Biol 1996, 26(1):101-109.

43. Kempton LRC, Isaac RE, Pillmoor JB, Willis RJ: Octopamine Nacteyltransferase activity from the cattle tick, Boophilus microplus. Insect Biochem Mol Biol 1992, 22:777-783.

44. Lees K, Bowman AS: Tick neurobiology: recent advances and the postgenomic era. Invert Neurosci 2007, 7:183-198.

45. Mather TN, Mather ME: Intrinsic competence of three ixodid ticks (Acari) as vectors for the Lyme disease spirochete. J Med Entomol 1990, 27:646-650.
46. Bradford M: A rapid and sensitive method for the quantitation of microgram quantities of protein utilizing the principle of protein dye binding. Anal Biochem 1976, 72:248-256.

47. Laemmli UK: Cleavage of structural proteins during the assembly of the head of bacteriophage T4. Nature 1970, 227:680-685.

48. Towbin H, Staehlin T, Gordon J: Electrophoretic transfer of proteins from polyacrylamide gels to nitrocellulose sheets: procedure and some applications. Proc Natl Acad Sci USA 1979, 76:4350-4354.

49. Binder TP, Duffel MW: Sulfation of benzylic alcohols catalyzed by aryl sulfotransferase IV. Mol Pharmacol 1988, 33:477-479.

doi:10.1186/1471-2091-12-32

Cite this article as: Pichu et al:: Molecular characterization of novel sulfotransferases from the tick, Ixodes scapularis. BMC Biochemistry 2011 12:32.

\section{Submit your next manuscript to BioMed Central and take full advantage of:}

- Convenient online submission

- Thorough peer review

- No space constraints or color figure charges

- Immediate publication on acceptance

- Inclusion in PubMed, CAS, Scopus and Google Scholar

- Research which is freely available for redistribution

Submit your manuscript at www.biomedcentral.com/submit
Biomed Central 